\title{
Physical activity and prevalence of diabetes in Melanesian and Indian men in Fiji
}

\author{
R. Taylor ${ }^{1,2}$, P. Ram ${ }^{3}$, P.Zimmet ${ }^{1}$, L. R. Raper ${ }^{1}$ and H. Ringrose ${ }^{4}$ \\ ${ }^{1}$ WHO Collaborating Centre for the Epidemiology of Diabetes Mellitus, Royal Southern Memorial Hospital, Melbourne, Australia, \\ ${ }^{2}$ South Pacific Commission, Noumea, New Caledonia, ${ }^{3}$ Colonial War Memorial Hospital, Suva, Fiji, and \\ ${ }^{4}$ Health Commission of Victoria, Melbourne, Australia
}

Summary. In Fiji Melanesian and Indian men, prevalence of diabetes is more than twice as high in those graded as sedentary or undertaking light activity as in those classed as performing moderate or heavy exercise. This difference was present in both ethnic groups, and maintained when age, obesity, and urban/rural status were taken into account. It is concluded that, in the population under study, there is epidemio- logical evidence for the role of physical inactivity as an independent risk factor for Type 2 (non-insulin-dependent) diabetes.

Key words: Type 2 diabetes, aetiology, physical activity, Melanesian men, Indian men.
Epidemiological studies in the Pacific Islands have demonstrated a higher prevalence of diabetes in urbanized and modernized populations than in those of the same ethnic group who reside in rural areas or outer islands and who continue to live a relatively traditional way of life [1-7].

Differences between such groups for possible determinants of diabetes mellitus have previously been documented. Rural and traditional-living populations are generally leaner, engage in more physical activity, and consume a diet containing more locally produced food when compared with urban and modernized communities [1-7].

Physical activity may play an independent role in protection against diabetes, apart from its role in the prevention or minimization of obesity [8]. Clinical and laboratory studies have demonstrated that physical training, even in the absence of weight loss, increases insulin sensitivity and improves glucose tolerance, whereas inactivity leads to a deterioration in glucose tolerance [9].

In this study, we look at the influence of the level of physical activity on the prevalence of diabetes mellitus in sample populations of Melanesian and Indian men from rural and urban areas of Fiji.

\section{Populations and methods}

\section{Background information}

Fiji is located in the south-west Pacific approximately halfway between Australia and Hawaii. The Fiji population is almost 600000, approximately $43 \%$ being Melanesian and $52 \%$ Indian in origin.

\section{Sampling}

Rural sample. The Sigatoka Valley was selected for the rural sample because it was the only relatively isolated rural area in Fiji where substantial numbers of Fijians and Indians live in close proximity, although usually in different settlements or villages.

The Melanesians selected were from villages situated by the river or in the hills; the major activity was subsistence farming.

The Indians included in the survey lived in settlements near the river flats and were engaged in farming - both subsistence and cashcropping (mostly sugar cane).

Urban sample. The Melanesian study population were from the Suva Fijian villages, the population of which is quite stable. These villages retain much of the traditional social organization characteristic of Fijian society, such as hereditary chiefs. Nevertheless the way of life is quite urbanized, with many persons earning wages. Virtually no subsistence or agricultural activity occurs around the villages.

The Indian subjects were from the suburb of Samabula, selected because it contains the highest density of Indian residents in Suva. Samabula is a typical suburb similar in many ways to those in a Western city. The residents of this area are mainly engaged in cash economy with at least one, and usually several, of the extended family employed (mostly males).

\section{Target population}

The target population consisted of all residents 20 years of age and over in the selected areas. The names of the subjects were obtained from the local health centre. The lists were updated before the survey by house-to-house visits by the local nursing staff.

\section{Response rates}

Good response rates were obtained in the urban populations (Melanesians, $88 \%$; Indians, $90 \%$ ). Because of heavy rain which caused flooding of rivers in the Sigatoka area, there were lower, but satisfactory, response rates among the rural populations (Melanesians, $83 \%$; Indians, $84 \%$ ). 
Table 1. Prevalence of diabetes, physical activity status and energy intakes of rural and urban Melanesian and Indian men in Fiji.

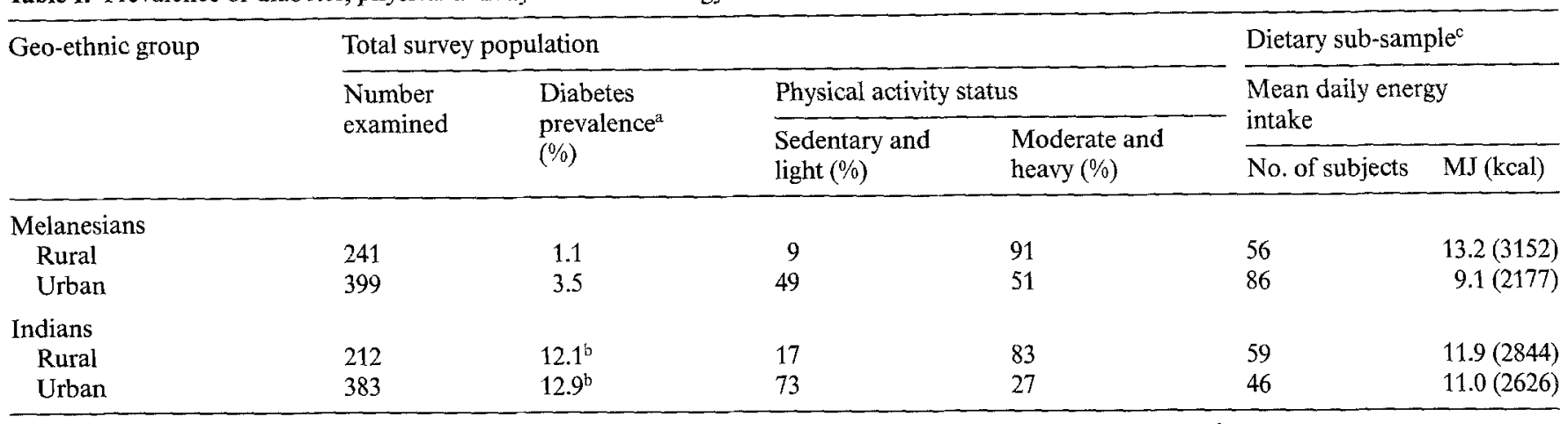

a Age-standardized to the age structure of the total population of Fiji at the 1976 census using the direct method; ${ }^{b} p<0.001$ Indian $>$ Melanesian within rural or urban groups; ${ }^{c}$ the dietary survey was conducted on an age-structured, randomly selected sub-sample, representing approximately $25 \%$ of the total survey population

The age and sex distribution of the survey population conformed closely to the age and sex distribution of the population of Fiji (Melanesians and Indians) at the 1976 national census.

Only men were included in the data analysis because they showed greater variation in the distribution of physical activity, with significant numbers at either extreme, than did women. Furthermore, the classification of physical activity was considered more accurate in men because most had an occupation which indicated the physical activity category to which they should be assigned.

\section{Survey procedure}

A fasting venous blood sample was taken and a 75 -g oral glucose load (as dextrose monohydrate in water) was administered. Following this details of the medical history and information on physical activity were collected. Height, weight, triceps skinfold thickness and other physical data were recorded. Two hours after the glucose load a further blood sample was taken. The blood was drawn into tubes containing $30 \mathrm{mg}$ sodium fluoride (Vacutainer, No.4752, Becton Dickinson, Rutherford, New Jersey). All blood samples were promptly centrifuged and separated, and 2-h plasma glucose values were measured on site with a glucose analyzer (model 23AM, Yellow Springs Instruments, Yellow Springs, Ohio, USA) which used a glucose oxidase method.

\section{Criteria for abnormal glucose tolerance}

The classification of abnormal glucose tolerance was based on current National Diabetes Data Group [10] and World Health Organization [11] criteria. Diabetes was diagnosed on the basis of a 2-h post-load plasma glucose concentration of $11.1 \mathrm{mmol} / 1(200 \mathrm{mg} / \mathrm{dl})$ or greater, or a history of known diabetes.

\section{Criteria for physical activity}

Physical activity was classified as (1) sedentary, (2) light, (3) moderate, and (4) heavy. Each person was assigned to one of the categories by the interviewers, who were local health staff. The interviewers were instructed to take occupation and other relevant information into account when classifying exercise.

'Sedentary' was applied to those who had office jobs, and 'heavy' was applied to those whose main occupation involved considerable manual labour, e.g. agriculture, public works, etc. 'Light' and 'moderate' were intermediate categories. 'Light' occupations included medical or hospital work, drivers, etc., and 'moderate' activity jobs included those who worked as tradesmen. After-hours sporting activity was taken into account in instances where it was substantial.

It has not been possible to verify the accuracy of the data on physical activity. This variable is notoriously difficult to measure, but it is probable that the categorical system used here in this study is no worse than any other practicable method.

For the purposes of analysis, the physical activity variable was dichotomized into a sedentary/light category and a moderate/heavy category. This decision was made to preserve numbers in the various sub-groups resulting from stratification of the population for analysis.

\section{Statistical methods}

Direct standardization was carried out using the age ranges 20-24, $25-34,35-44,45-54,55-64$, and $65+$ years; the significance of the differences between age-standardized rates was calculated using $\chi^{2}$ according to the method described by Armitage [12]. Mean values were adjusted for the influence of covariants and factors, using analy. sis of covariance [13].

Adjustment of diabetes prevalence in each exercise category for the effect of age, triceps skinfold thickness and urban/rural residence was accomplished using a combination multivariate/stratification method described by Miethinen [14] and used recentiy by Knowler et al. [15]. Firstly, a multiple linear regression of diabetes (0.1) on age, physical activity $(0.1)$, triceps skinfold thickness and urban/rural residence (0.1) was performed. (Note that categorical variables were designated as zero or unity). Multiplicative and squared terms were included in order to take account of interactions and non-linear relationships. Melanesians and Indians were analysed separately.

A 'risk-indicator' score was then computed for each case, using the constant and coefficients obtained from the regression analysis and the individual's actual values of each variable, except that the physical activity was 'fixed' at zero. The subjects were then stratified into quintiles according to their 'risk-indicator' score, and diabetes prevalence tabulated by physical activity within each quintile. Diabetes prevalence can be directly compared within each of these risk categories relatively free of confounding influences. Summary rates and relative risk can be computed by direct standardization [12] using the total population structure stratified by risk category as the standard, or using the Mantel-Haenszel method [16]. A summary $\chi^{2}$ statistic can be computed for comparison of the overall diabetes prevalence in each exercise category.

\section{Results}

An urban/rural differential in prevalence of diabetes was observed in Melanesians, but not amongst Indians, who had much higher rates of diabetes (Table 1).

The rural populations were more active and consumed more calories (particularly Melanesians, Table 1), while indices of obesity, such as body mass in- 


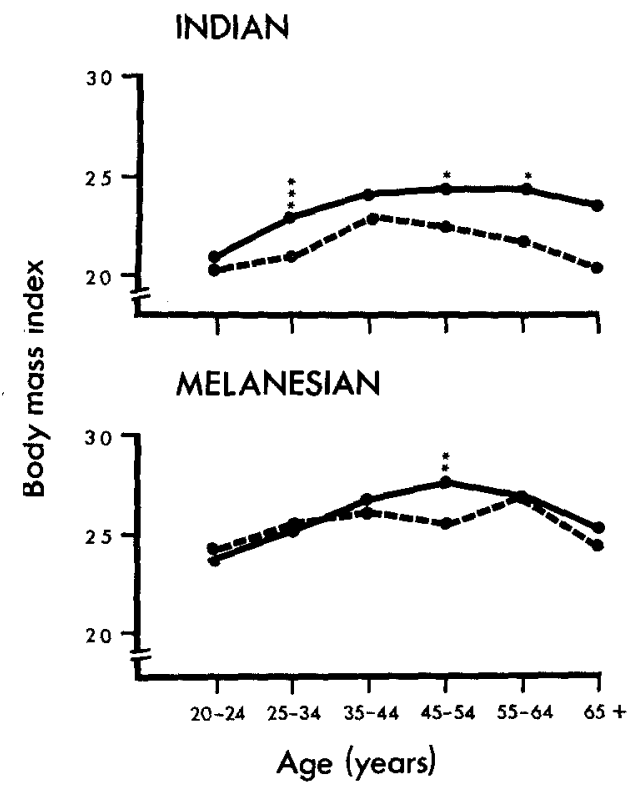

Fig. 1. Mean body mass index against age groups for rural and urban Indian and Melanesian men. ${ }^{*} p<0.05 ;{ }^{* *} p<0.01 ;{ }^{* * *} p<0.001$

\section{INDIAN}

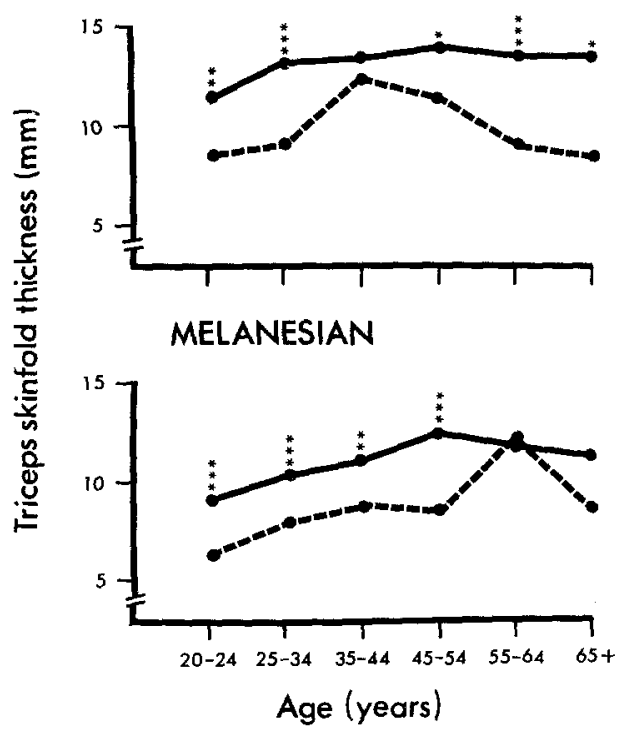

Fig. 2. Mean triceps skinfold thickness against age group for rural and urban Indian and Melanesian men. ${ }^{*} p<0.05 ;{ }^{* *} p<0.01$; $* * * p<0.001$

dex and triceps skinfold thickness, were higher in the urban groups (Figs. 1 and 2). This suggests that triceps skinfold thickness may be better than body mass index as a discriminator for obesity between rural and urban populations in Fiji, particularly for Melanesians (presumably because of the partial dependence of body mass index on muscularity). Furthermore, although Melanesians had higher body mass indices than Indians, according to triceps skinfold thickness measurements the Indians were fatter. Ethnic differences in frame size and degree of muscularity are obviously important here. The ethnic groups have therefore been analysed separately.

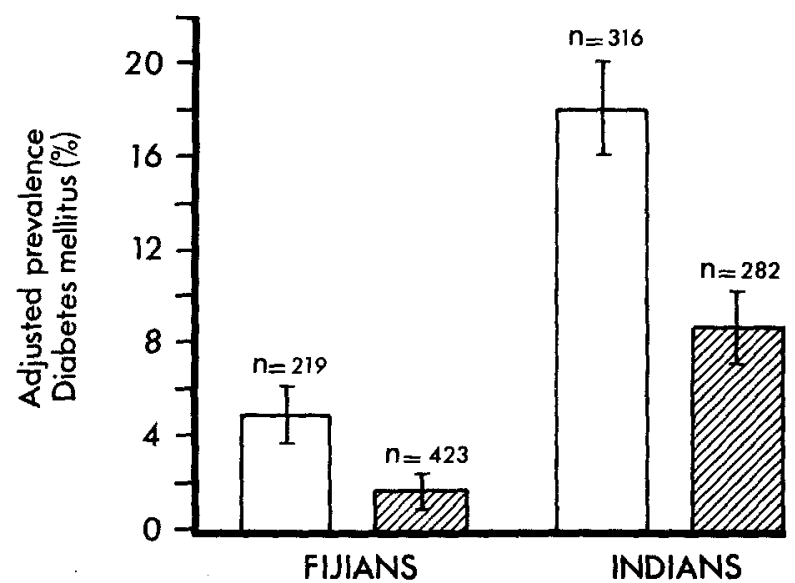

Fig.3. Prevalence of diabetes adjusted for triceps skinfold thickness, age and urban/rural residence in sedentary/light ( $\square$ compared with moderate/heavy $(Z)$ exercise categories in Fijian Melanesian and Indian men analysed separately

The characteristics of the two ethnic groups divided according to physical exercise status with respect to age-adjusted mean body mass index, mean triceps skinfold thickness, and diabetes prevalence are set out in Table 2 . There were no consistent, statistically significant differences in measures of obesity between the two exercise categories in either ethnic group. However, there is a consistent trend for the age-adjusted diabetes prevalence to be higher in the sedentary/light category than in those classified as undertaking moderate/heavy activity. The differences are statistically significant for both the rural and the pooled rural and urban populations.

Mean 2-h plasma glucose adjusted for age and age and triceps skinfold thickness were consistently higher in those performing sedentary/light activity than in the moderate/heavy activity group (Table 3 ). These differences did not reach statistical significance, except in the pooled Melanesian group.

The prevalence of diabetes in the various 'risk indicator' categories for the two exercise groups is shown in Table 4. Comparisons between the exercise categories can be made relatively free from confounding by age, triceps skinfold thickness or urban/rural status. Summary rates and statistics indicate a higher prevalence of diabetes in the sedentary/light group than in the moderate/heavy category. The ratio of rates was 2.5 for Fijians $\left(\chi^{2}=3.9 ; p \leqq 0.05\right)$ and 2.1 for Indians $\left(\chi^{2}=13.0\right.$; $p \leqq 0.001$ ) (Fig.3).

\section{Discussion}

The results of this study show that there is a difference in the prevalence of diabetes and mean 2-h plasma glucose level between men categorized as undertaking sedentary/light physical activity, and those classified as performing moderate/heavy exercise. These differences are consistent in all sub-groups and statistically signifi- 
Table 2. Age-adjusted ${ }^{\mathrm{a}}$ mean body mass index, mean triceps skinfold thickness and prevalence of diabetes ${ }^{\mathrm{b}}$ by physical activity category in Me- $^{-}$ lanesian and Indian men in Fiji

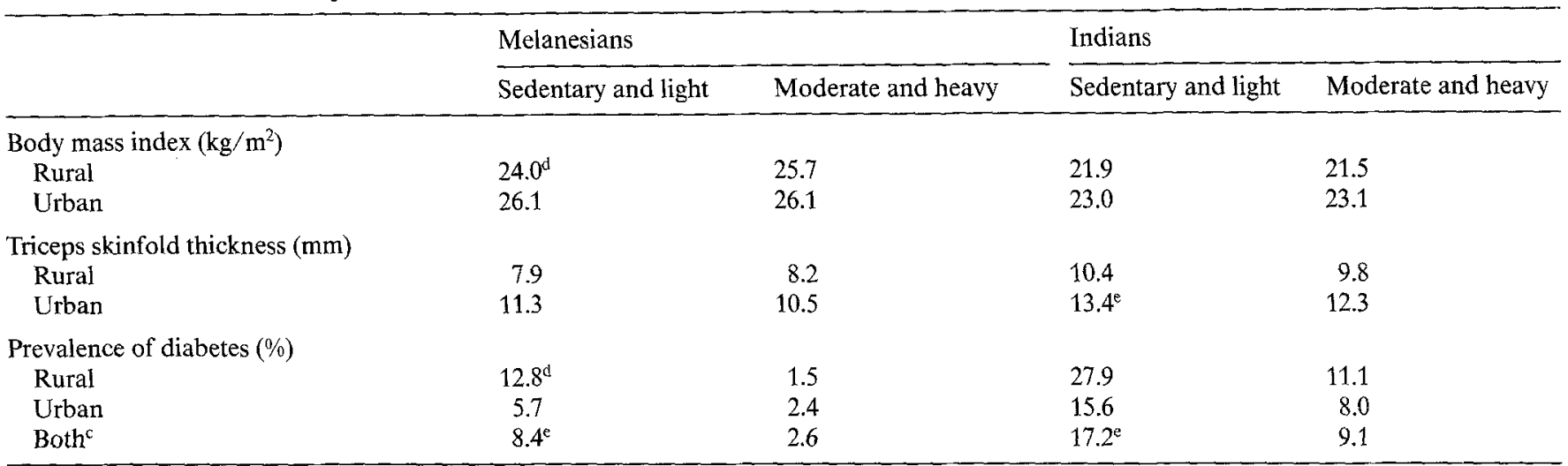

${ }^{a}$ Adjusted for mean age of both exercise categories in each sub-group by analysis of covariance; ${ }^{b}$ age-adjusted by the direct method to the total age structure of each ethnic group; ${ }^{\mathrm{c}}$ adjusted for age and urban/rural status; ${ }^{d} p<0.05 ;{ }^{\mathrm{e}} p<0.01$ for comparisons with moderate/heavy exercise category

Table 3. Mean 2-h plasma glucose adjusted ${ }^{a}$ for age and triceps skinfold thickness, by physical activity category in rural and urban Melanesian and Indian men in Fiji

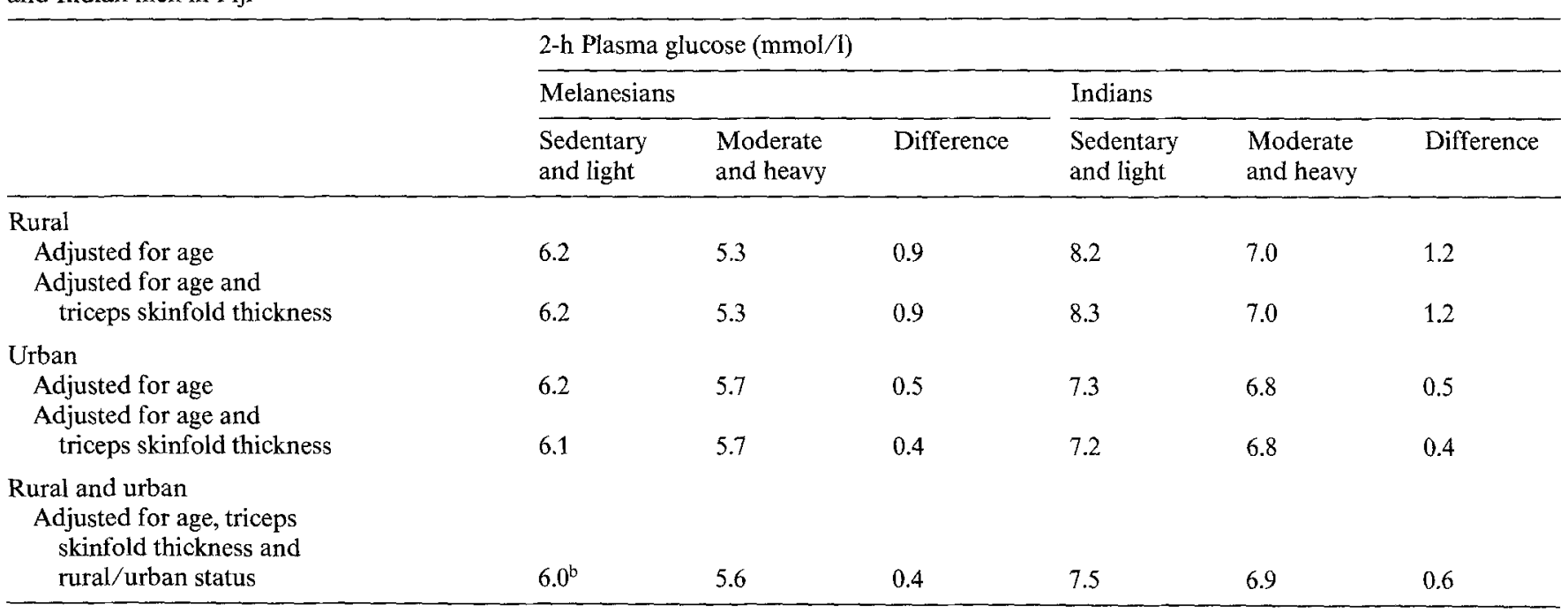

asing analysis of covariance to adjust 2-h plasma glucose. Covariates: triceps skinfold thickness and age. Factors: urban or rural status;

${ }^{b} p=0.033$ for differences between activity categories

Table 4. Prevalence of diabetes adjusted for age, triceps skinfold thickness and rural/urban residence in Melanesian and Indian males in Fiji

\begin{tabular}{|c|c|c|c|c|c|c|c|c|}
\hline \multirow{3}{*}{$\begin{array}{l}\text { Quintiles } \\
\text { of 'risk } \\
\text { indicator' } \\
\text { score }\end{array}$} & \multicolumn{8}{|c|}{ Prevalence of diabetes $(\%)$} \\
\hline & \multicolumn{2}{|c|}{ Sedentary and light } & \multicolumn{2}{|c|}{ Moderate and heavy } & \multicolumn{2}{|c|}{ Sedentary and light } & \multicolumn{2}{|c|}{ Moderate and heavy } \\
\hline & No. & $\%$ & No. & $\%$ & No. & $\%$ & No. & $\%$ \\
\hline 1 & $0 / 31$ & 0 & $0 / 93$ & 0 & $1 / 70$ & 1 & $0 / 47$ & 0 \\
\hline 2 & $0 / 39$ & 0 & $0 / 89$ & 0 & $1 / 65$ & 2 & $0 / 57$ & 0 \\
\hline 5 & $12 / 73$ & 16 & $2 / 59$ & 3 & $26 / 63$ & 41 & $16 / 60$ & 27 \\
\hline $\begin{array}{l}\text { Standardized } \\
\text { rate }(\%)\end{array}$ & $5.0^{\mathrm{a}}$ & & 2.0 & & $18.1^{\mathrm{b}}$ & & 8.8 & \\
\hline Ratio of rates & & 2.5 & & & & 2.1 & & \\
\hline
\end{tabular}

Standardized by the direct method to the population structure according to stratification by 'risk-indicator' score status for each ethnic group separately. Mantel-Haenszel computations yield similar relative risk and $\chi^{2}$ values.

${ }^{a} p<0.05 ;{ }^{b} p<0.001$ for comparison between activity categories 
cant when certain sub-groups are aggregated. On the other hand, there are no consistent significant differences in obesity (as measured by triceps skinfold thickness or body mass index) between the two main physical activity categories in each ethnic group.

The difference in diabetes prevalence and mean 2-h plasma glucose between the two physical activity categories remains when the confounding effects of age and obesity (measured by triceps skinfold thickness) are taken into account. The differences are of considerable magnitude, with relative risks in excess of two for diabetes prevalence.

There may be other reasons for the association of diabetes with low physical activity (controlling for the effect of obesity) than a direct causal relationship. It could be argued that the association between low physical exercise and diabetes mellitus is due to impaired physical capacity in those who are incapacitated by diabetes mellitus. However, Type 2 diabetes is often asymptomatic in Pacific populations until the onset of complications [17]. Furthermore, the activity classification was made principally on the basis of occupation, and it is difficult for people to change from manual to sedentary occupations - the latter usually requiring considerably more education.

It is also possible that physical activity is a marker for other environmental factors, and it may be that there are subtle but important differences in diet between those engaged in moderate/heavy exercise and those undertaking sedentary/light activity.

The evidence presented in this article outlines an association of Type 2 diabetes with low physical activity which appears to be independent of obesity. A possible physiological explanation is that both physical fitness and acute exercise may relieve the pancreatic beta cells of the need to secrete copious amounts of insulin in response to ingested glucose, and over several decades this may protect susceptible cells from failure.

It is well established that physical training results in increased insulin sensitivity in peripheral tissues, especially muscles [9]. Evidence is accumulating that a major characteristic of Type 2 diabetes is insulin resistance at the level of the target tissues - possibly a post-receptor defect [18]. The cause of this insulin resistance is not known but it is possible that a sedentary way of life could be one of a number of factors causing insulin resistance in an individual with a genetic susceptibility to diabetes. Physical exercise has been recommended as part of the therapy for Type 2 diabetes because of the increased insulin sensitivity produced [9].

This study highlights an epidemiological association between a sedentary way of life and prevalence of diabetes in two ethnic groups. Clearly, much more physiological and clinical research is necessary to elucidate the specific mechanisms as to how reduced physical activity plays a pathogenic role in Type 2 diabetes.
Acknowledgements. NIH Grant No. AM 25446 is gratefully acknowledged.

\section{References}

1. Prior I, Davidson F (1966) The epidemiology of diabetes in Polynesians and Europeans in New Zealand and the Pacific. NZ Med J 65: 375-383

2. Prior I, Rose B, Harvey H, Davidson F (1966) Hyperuricaemia, gout, and diabetic abnormality in Polynesian people. Lancet 1: 333-338

3. Zimmet P, Faaiuso S, Ainuu J, Whitehouse S, Milne B, DeBoer W (1981) The prevalence of diabetes in the rural and urban Polynesian population of Western Samoa. Diabetes 30:45-51

4. Reed D, Labarthe D, Stallones R, Brody J (1973) Epidemiologic studies of serum glucose levels among Micronesians. Diabetes 22: 129-136

5. Taylor RJ, Bennett PH, LeGonidec G, Lacoste J, Combe D, Joffres M, Uili R, Charpin M, Zimmet P (1983) The prevalence of diabetes mellitus in a traditional-living Polynesian population. The Wallis Island Survey. Diabetes Care 6: 334-340

6. Martin F, Wyatt G, Griew A, Haurahelia M, Higginbotham L (1980) Diabetes mellitus in urban and rural communities in Papua New Guinea. Diabetologia 18: 369-374

7. Zimmet P, Taylor R, King HOM, Pargeter K, Geddes W (1981) Report to Australian Development Assistance Bureau of the diabetes and cardiovascular disease survey, Kiribati. WHO Collaborating Centre for the Epidemiology of Diabetes Mellitus, Melbourne, Australia

8. Taylor R, Zimmet P (1983) Epidemiology of diabetes: migrant studies. In: Mann JI, Pÿlörä K, Teuscher A (eds) Diabetes in epidemiological perspective. Churchill Livingstone, New York, pp 58-77

9. Björntorp P (1982) Effects of physical training on diabetes mellitus, Type II. In: Bostrom $\mathrm{H}$, Ljungstedt $\mathrm{N}$ (eds) Recent trends in diabetes research. Almquist \& Wiksell International, Stockholm, pp 115-125

10. National Diabetes Data Group (1979) Classification and diagnosis of diabetes mellitus and other categories of glucose intolerance. Diabetes 28: 1039-1057

11. World Health Organization Expert Committee on Diabetes Mellitus, Second Report (1980) Technical Report Series, No.646, WHO Geneva

12. Armitage P (1971) Statistical methods in medical research. Blackwell, Oxford, $\mathrm{p} 387$

13. Nie NH, Hull CH, Jenkins JG, Steinbrenner K, Bent DH (1975) Statistical Package for the Social Sciences. 2nd edn. McGraw Hill, New York

14. Miethinen $O$ (1976) Stratification by multivariate confounder score. Am J Epid 104: 609-620

15. Knowler W, Bennett $P$, Ballintine $F(1980)$ Increased incidence of retinopathy in diabetes with elevated blood pressure. New Engl J Med 302: 645-649

16. Mantel N, Haenszel W (1959) Statistical aspects of analysis of data from retrospective studies of disease. $\mathrm{J}$ Natl Cancer Inst 22: $719-748$

Received: 9 December 1983

and in revised form: 10 September 1984

Dr. R. Taylor

South Pacific Commission

B.P. D5, Noumea

New Caledonia 